\title{
What Factors Determine Public Acceptance for Nuclear Power Stations
}

\section{-Learning from Public Survey in Area of Hamaoka Power Station-}

\author{
Tokoha University, Ryuzo Yamamoto
}

\begin{abstract}
Papers from other countries on public acceptance of nuclear power and a survey that we conducted in four cities near the Hamaoka Nuclear Power Plant have demonstrated that people interested in the issues of energy supply and climate change recognize more of the benefits of nuclear energy. The level of public acceptance depends on the timing and country. Analysis of such differences will probably offer clues on how to obtain a deeper understanding of nuclear energy among the public. Furthermore, analysis of the ways in which people perceive the benefits of nuclear energy and how they compare these benefits against the risks will enable us to identify ways of helping them obtain a deeper understanding of nuclear energy.
\end{abstract}

KEYWORDS: Hamaoka Nuclear Power Plant, climate change, energy security, energy price, public opinions, social acceptance

\section{Introduction}

An energy supply policy pursues the reliable and safe delivery of competitive, environmentally friendly energy and power to consumers. Public opinion on nuclear power naturally depends on how well the policy goal of the 3Es (economics, environment, and energy security) plus $\mathrm{S}$ (safety) is achieved.

One advantage of nuclear energy is that it can economically and reliably provide consumers with affordable electric power with marginal carbon emissions. However, the perceived disadvantages are also great due to the risk of severe accidents that could lead to radiation leaks as well as problems involving the disposal of nuclear waste. As such, public opinion varies depending on how these advantages and disadvantages are evaluated in different countries at different times.

For instance, people with a strong interest in global warming and climate change tend to be more supportive of nuclear power. Furthermore, the emergence of any energy security challenges is expected to increase the share of those in favor of nuclear energy. The most desirable form of education on energy can be explored by examining the relationship between the level of public acceptance of nuclear power and the level of interest in energy policies.

DOI : 10.15669/fukushimainsights.Vol.3.210

(c) 2021 Atomic Energy Society of Japan. All rights reserved.

Originally published in Journal of the Atomic Energy Society of Japan (ISSN 1882-2606), Vol. 58, No. 7, p. 424-428 (2016)

in Japanese. (Japanese version accepted: April 11, 2016) 
In last month's commentary (page 191-198 of this volume) we reported the results from a questionnaire survey conducted in four cities near the Hamaoka Nuclear Power Plant, which is located in Shizuoka Prefecture. The survey also examined the correlation between the level of interest in the four energy policy issues and the level of acceptance of nuclear power among respondents. These findings are analyzed to consider what factors require particular emphasis in educational activities related to energy.

\section{Why Does Public Acceptance of Nuclear Power Fluctuate?}

At times, public acceptance of nuclear power can fluctuate significantly. For instance, the share of people in favor of nuclear energy dropped in many countries after the Chernobyl Accident and the Fukushima Daiichi Nuclear Accident. In contrast, support for nuclear energy strengthened rather than weakened in the United Kingdom. What influences public acceptance? This section reviews earlier studies to examine the varying reasons of public acceptance of nuclear energy in different times and countries.

\section{Changes in Public Opinion Over Time}

American people are generally in favor of nuclear energy. Except for the temporary reversal that occurred after the Three Mile Island Accident, more Americans have indicated that they are in favor rather than against it since the early days of nuclear power until the survey last year.

Professor Michael Golay of the Massachusetts Institute of Technology divides the history of nuclear power in the United States into the following three phases ${ }^{1)}$.

1) Initial optimism during the first half of the Vietnam War up to 1968 under the Eisenhower and Kennedy administrations

2) Doubts, criticism, and pessimism after the Vietnam War

3) A tailwind for nuclear energy during the economic expansion from the early 1990s

The balance between support and opposition to nuclear energy in each of the phases reflects the prevailing economic and social conditions. Conceivably, the balance may also have been influenced by the organizational performance of stakeholders in the nuclear sector. Professor Golay excludes any technological influence on public opinion given that the equipment used in nuclear power generation has not evolved much throughout the three phases. The professor summarizes these three phases as described below.

From the first half of the Vietnam War until the mid-1960s, the American public was highly appreciative of nuclear power. The idea of using nuclear aircraft and rockets was widely supported, and universities were eager to set up their own nuclear research reactors. In fact, power utilities without nuclear power plants were considered backward. The order placement and planning stages for most currently operational plants date back to this phase.

During the economic stagnation and uncertainty that followed, from the intensification of the Vietnam War in the mid-1960s through to the early 1990s, US politics was caught up in disagreements over the future of the country. Public opinion on nuclear energy was also influenced by this uncertainty. The risk of nuclear accidents and issues concerning nuclear waste disposal had been pointed out even before the Three Mile Island Accident.

The robust economic growth that was experienced from the early 1990s bolstered national confidence and optimism, which helped dispel concerns over nuclear energy to some extent. 
The steady enhancement of plant capacity utilization — typically by $20 \%$-also tilted public opinion in favor of nuclear power. According to a Gallup poll conducted in 1994, 57\% of respondents in the United States were in favor of nuclear power while $37 \%$ were opposed.

\section{Changes in Public Opinion in Different Countries}

In the European Union, 15 member countries operate 131 nuclear power reactors, thereby covering $27 \%$ of their power needs. According to a survey published in 2014, energy is not a high-profile issue. Only $14 \%$ of respondents indicated an interest in energy issues, as compared to unemployment (64\%), crime (36\%), and health insurance system (30\%) ${ }^{2}$. Another possible reason for the considerable variations in public opinion among different countries may be differences in the ways that surveys are conducted or questions are framed in surveys.

For instance, people are more likely to respond that nuclear energy is necessary if the question is asked in relation to the response to global warming. When asked to choose between the continued operation and additional construction of nuclear power plants, more respondents will shy away from the latter, thereby diminishing the share of pro-nuclear responses. The European Nuclear Energy Forum asks the same questions to clarify the varying degrees of public support toward nuclear energy among major European countries.

These differences can probably be ascribed to cultural backgrounds in the respective countries and public attitudes toward energy security, and global warming and climate change. The circumstances in some European countries are presented here to consider the reasons behind the varying levels of public acceptance of nuclear energy.

Finland has constructed the Onkalo (the Finnish word for "cave") disposal site for high-level waste. In a survey conducted in $2014,41 \%$ of respondents supported nuclear power, while $24 \%$ were against it. Nuclear power is widely discussed in Finland. Finns are known to be pragmatic, and they probably consider it risky to depend on Russia for their energy supply.

France covers more than $70 \%$ of its power needs with 58 nuclear power reactors, the second largest number after the United States. The experience of the 1973 oil crisis prompted France to adopt nuclear power to ensure a secure energy supply. Educational activities related to energy issues are being conducted extensively for French citizens. Study tours of nuclear power plants are organized in earnest for schools and workplaces. When asked how they regard this considerable dependency on nuclear energy for their power supply, the majority consistently responded that it brings advantages to France until this view was suddenly reversed when the majority recognized more disadvantages in 2012 in the immediate aftermath of the Fukushima Nuclear Accident. In the next survey conducted in 2013, however, pro-nuclear views prevailed again, with $48 \%$ of respondents viewing nuclear power as advantageous against $36 \%$ viewing it as disadvantageous.

In another survey conducted in the United Kingdom by the Department of Energy and Climate Change in March 2014, $42 \%$ of respondents were in favor of nuclear power, 20\% were opposed, and $38 \%$ had no opinion. The reasons for this high public acceptance of nuclear energy include a high level of interest in energy security and climate change among British people, who are concerned over the diminishing production of domestic coal as well as petroleum and natural gas from the North Sea. Both the government and citizens seem to recognize that renewable energy alone cannot address these issues adequately.

Prompted by the Fukushima Daiichi Nuclear Accident, Germany officially decided in August 2011 to shut down eight nuclear power reactors that had begun operating before 1980 . Nine nuclear power reactors that are currently still in operation will also be shut down by 2022. In a survey conducted in April 2014, 52\% of respondents opposed the idea of revising 
the country's energy policy of decommissioning nuclear power plants for the sake of energy security. In other words, more than half of the nation supports the current government policy of opting away from nuclear energy.

Public opinion seems to vary in different countries due to differences in their understanding of issues related to energy security, climate change, energy prices, and accidents at nuclear power plants. In the next section, we trace changes in public opinion associated with the Fukushima Daiichi Nuclear Accident to examine how public opinion is influenced by the public's level of understanding of energy policies.

\section{Impact of the Fukushima Daiichi Nuclear Accident on Public Opinion}

From June to September 2011, the BBC conducted a public opinion poll on nuclear and renewable energy in 23 countries, including 12 countries with nuclear power plants ${ }^{3)}$. An earlier survey was conducted with eight countries in 2005.

In 2011, the following 12 countries with nuclear power plants took part in a survey on nuclear power: Brazil, China, France, Germany, India, Japan, Mexico, Pakistan, Russia, Spain, the United Kingdom, and the United States. In total, $22 \%$ of the respondents believed that new plants should be constructed, 39\% favored continuing the operation of existing plants but not constructing any new ones, and $30 \%$ thought that existing plants should be shut down immediately.

Support for the construction of new nuclear power plants varies greatly from one country to the next. The high level of support found in China (42\%), Pakistan (39\%), the United States (39\%), and the United Kingdom (37\%) is in stark contrast to the less than 10\% support found in Japan, Germany, Russia, and Spain.

Figure 1 compares opinions on the future of nuclear power in 2005 and 2011 according to the results of a survey conducted in five countries (Germany, France, the United Kingdom, the United States, and Japan). Calls for an immediate shutdown grew louder in Germany, France, and Japan, but weakened in the United Kingdom and United States despite the fresh memory of the Fukushima Daiichi Nuclear Accident.

This weaker opposition to nuclear energy in the United Kingdom and the United States is probably due to the majority believing that the perceived benefits outweigh the perceived risks, even after the accident in Fukushima. A large number of respondents from China and

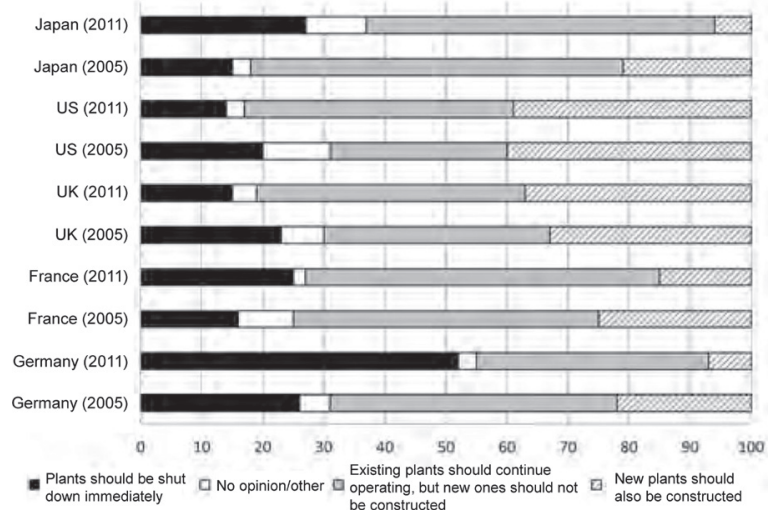

Figure 1 Changes in public opinion on nuclear power Source: BBC World Service Poll, November 2011 
Pakistan support the construction of new plants, and this is probably because of the perceived benefits of nuclear energy against the backdrop of an expected surge in energy demand.

So, why do the British public and the American public perceive greater benefits and endorse nuclear energy more than people in other countries do? In the next section, we consider this question based on public opinion surveys conducted in these two countries.

\section{Perceived Benefits of Nuclear Power}

Nuclear power improves a country's energy self-sufficiency and makes electricity prices more stable. Furthermore, this low-carbon source of power also helps curb climate change. In spite of the risks associated with severe accidents and waste disposal, nuclear energy is employed by many countries because the risks are outweighed by the benefits. Nonetheless, the perceived benefits and risks vary depending on cultural backgrounds and other factors among different countries.

\section{British Sensitivity to Climate Change}

Most of the British public have an interest in the issues of climate change and energy security. In addition, many think that renewable energy sources alone are not enough to tackle climate change. Hence, nuclear energy is widely supported there, even after the Fukushima Nuclear Accident ${ }^{4}$.

Figures 2 and $\mathbf{3}$ show British perceptions of nuclear energy and climate change, respectively. The slight drop in the share of people who are concerned about climate change observed from 2012 to 2013 is probably due to an increase in the number of people who accept some of the arguments presented by global warming skeptics. This drop has also chipped

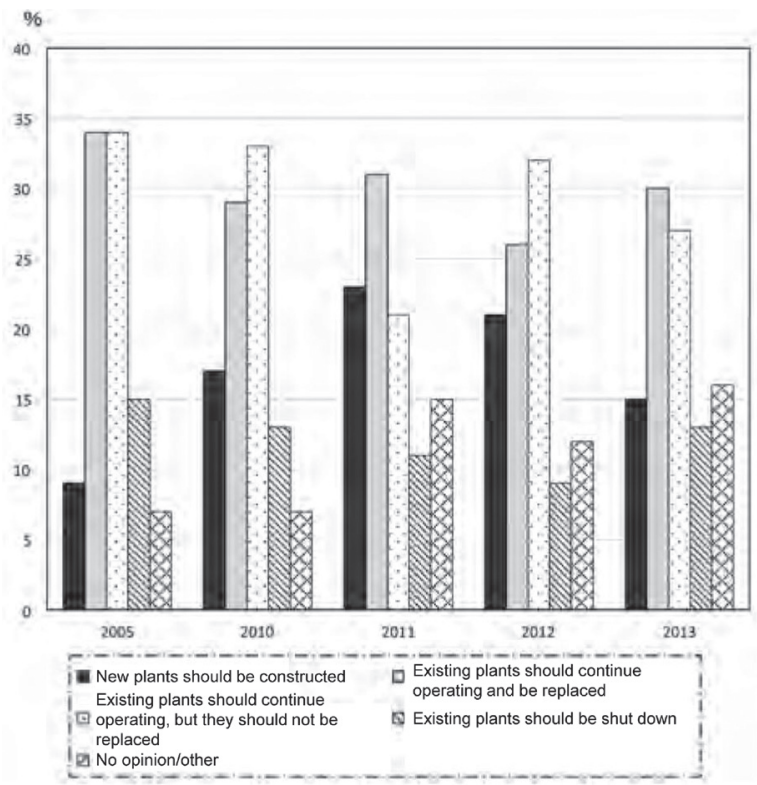

Figure 2 British public opinion on nuclear power generation ${ }^{4)}$ 


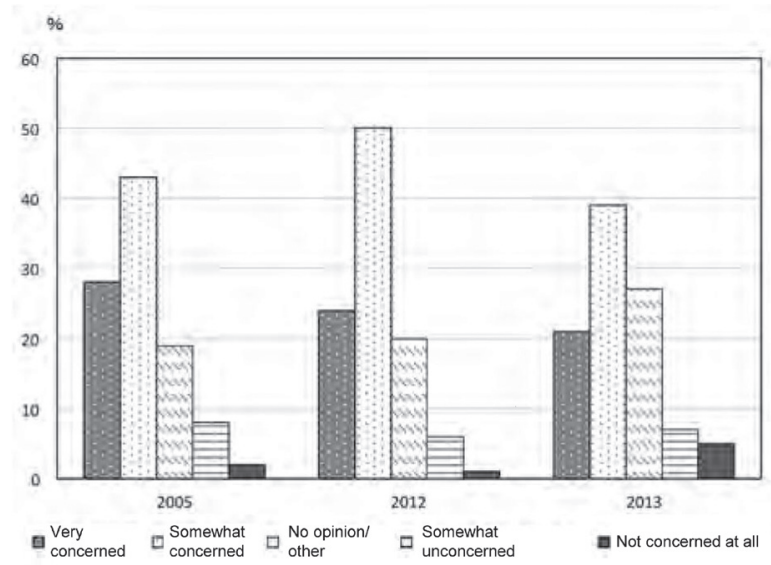

Figure 3 Are you concerned about climate change? ${ }^{4)}$

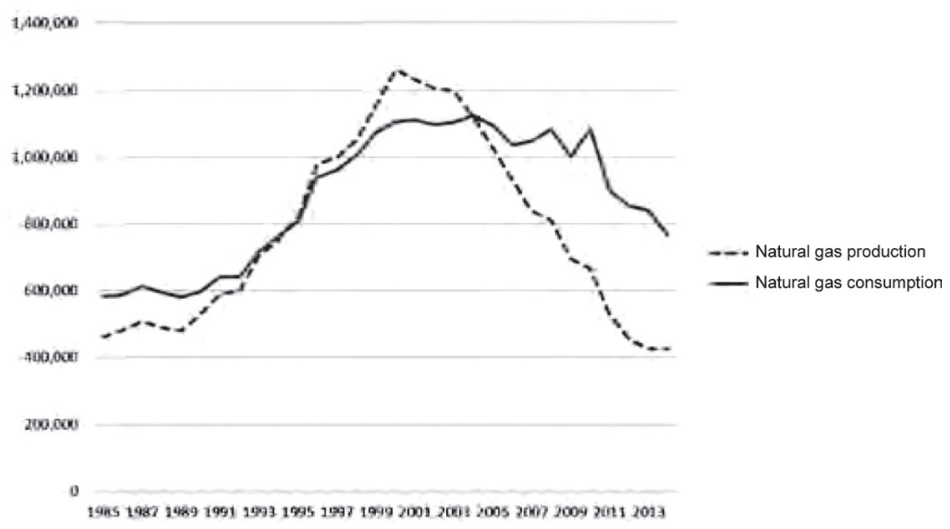

Figure 4 Natural gas production and consumption in the United Kingdom Source: British Department of Energy and Climate Change

away at some of the support for the construction of new nuclear power plants.

In a survey conducted in $2013,37 \%$ of the respondents believed that the perceived benefits of nuclear power were greater than the perceived risks, $29 \%$ believed that the reverse was true, and $20 \%$ believed that they were balanced. The benefits of nuclear power seem to be recognized by most citizens in the United Kingdom. Indeed, $47 \%$ of them agree with the construction of new plants if doing so helps to address climate change, while $24 \%$ are opposed. Similarly, 52\% agree if doing so helps to enhance energy security, while $22 \%$ are opposed. One possible reason for this is the reduced natural gas production in the North Sea and the resultant decline in the country's energy self-sufficiency as shown in Figure 4.

\section{American Sensitivity to Energy Prices}

In March 2016, a Gallup poll revealed for the first time that more than half of American respondents were opposed to nuclear energy ${ }^{5}$. Public acceptance of nuclear power stood at around 57\% even in a survey conducted in 2012 in the aftermath of the Fukushima Daiichi Nuclear Accident. In fact, the level of support remained the same as that observed in the 


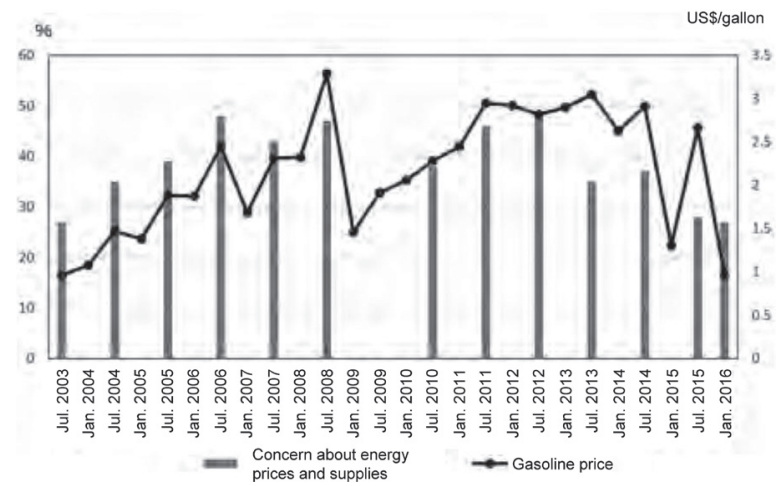

Figure 5 Gasoline prices and concern about energy supplies

Note: No survey was conducted in 2009. Even if a set of results is labelled "July," it does not necessarily mean that the survey was actually conducted in July.

Source: Gasoline prices according to the US Energy Information Administration and percentage of concerned respondents according to a Gallup poll

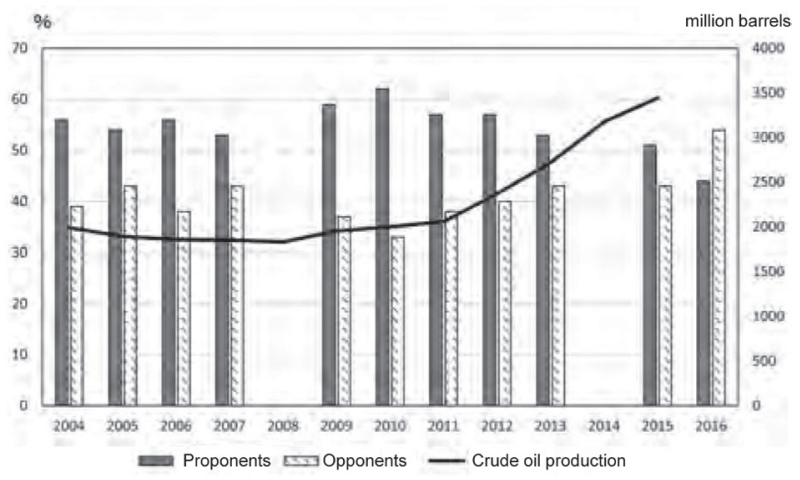

Figure 6 Crude oil production and changes in public acceptance of nuclear energy Note: No surveys were conducted in 2008 and 2014.

Source: US Energy Information Administration and Gallup

previous survey before the accident. Given this, it is clear that the subsequent decline in acceptance was not due to concerns about severe accidents.

Another public opinion survey on energy issues that was conducted around the same time revealed a record low percentage of respondents concerned about energy supplies and prices. The factors underlying this are increases in shale oil and gas production in the United States along with a continuous decline in the oil price. Thanks to this shale oil production, the United States overtook Saudi Arabia to become the world's top oil producer. The United States also became the top producer of shale gas. In February this year (2016), exports of liquefied natural gas began for the first time in a state other than Alaska.

The shale revolution has turned the United States into the top producer of oil and natural gas. Combined with the declining oil price, this development has helped to defuse concerns about energy security. As shown in Figure 5, the declining gasoline price in the United States has helped Americans shake off the sense of crisis that they had over energy supplies. Figure 6, which compares changes in domestic oil production and public acceptance of nuclear energy in the United States, implies that fading concerns over energy supplies and prices tend to reduce public support for nuclear energy. 
Table 1 Are nuclear power plants necessary to ensure a reliable power supply?

\begin{tabular}{|lll|}
\hline & $\begin{array}{l}\text { Knew about } \\
\text { additional fuel costs }\end{array}$ & $\begin{array}{l}\text { Did not know about } \\
\text { additional fuel costs }\end{array}$ \\
\hline Responses & 3026 & 4333 \\
\hline Definitely necessary & 22.7 & 9.7 \\
\hline $\begin{array}{l}\text { Somewhat } \\
\text { necessary }\end{array}$ & 28.2 & 30.1 \\
\hline $\begin{array}{l}\text { Somewhat } \\
\text { unnecessary }\end{array}$ & 17.5 & 23.6 \\
\hline $\begin{array}{l}\text { Definitely } \\
\text { unnecessary }\end{array}$ & 29.3 & 29.4 \\
\hline No opinion & 2.3 & 7.1 \\
\hline
\end{tabular}

Table 2 Are nuclear power plants necessary for curbing global warming?

\begin{tabular}{|lll|}
\hline & $\begin{array}{l}\text { Knew about Japan's } \\
\text { emissions reduction } \\
\text { target }\end{array}$ & $\begin{array}{l}\text { Did not know about } \\
\text { Japan's emissions } \\
\text { reduction target }\end{array}$ \\
\hline Responses & 3963 & 3397 \\
\hline Definitely necessary & 15.4 & 9.5 \\
\hline $\begin{array}{l}\text { Somewhat } \\
\text { necessary }\end{array}$ & 27.1 & 25.1 \\
\hline $\begin{array}{l}\text { Somewhat } \\
\text { unnecessary }\end{array}$ & 22.0 & 26.5 \\
\hline $\begin{array}{l}\text { Definitely } \\
\text { unnecessary }\end{array}$ & 30.8 & 27.1 \\
\hline No opinion & 4.7 & 11.7 \\
\hline
\end{tabular}

\section{Awareness among Communities Near the Hamaoka Nuclear Power Plant}

The survey that we conducted in four cities located near the Hamaoka Nuclear Power Plant was designed to examine if the level of support for nuclear power varies depending on interest in energy security, fuel prices, and climate change.

In this survey, questions were also asked to determine whether the respondents had any knowledge of matters such as the level of energy self-sufficiency in Japan, the 2015 United Nations Climate Change Conference (COP 21), Japan's greenhouse gas emissions target for 2030, the additional fuel costs, and increased electricity prices.

Most respondents knew about COP 21, energy self-sufficiency, and the increase in electricity prices. However, the responses were roughly split in two with respect to whether they knew about Japan's emissions target and the necessary additional fuel costs. The responses were analyzed to determine how the respondents' knowledge or ignorance of these two issues related to global warming and energy supplies influenced their acceptance of nuclear power.

The results summarized in Tables $\mathbf{1}$ and $\mathbf{2}$ demonstrate that respondents with a greater interest in the issues of energy supplies and climate change tend to favor nuclear power. As mentioned in the previous commentary, negative views on nuclear power may be more pronounced due to the composition of respondents not reflecting the actual age structure of Japan's population. Adjusted by age, the share of responses in favor of nuclear power would increase, reflecting their relatively greater interest in these issues. 


\section{For Building a Deeper Understanding of Nuclear Power}

The results of various surveys on nuclear power conducted in the United Kingdom and the United States as well as one conducted near the Hamaoka Nuclear Power Plant demonstrate that the level of understanding of nuclear power is strongly correlated with knowledge of issues related to energy security, energy prices, and climate change.

Promoting a deeper understanding of issues concerning energy supplies, and climate change and global warming clearly enhances public acceptance of nuclear power. Furthermore, as shown by the results of a survey conducted in the United Kingdom, for example, climate change skepticism can reduce support for nuclear power. Instead of stressing a specific benefit, we need to consider all of the advantages of nuclear energy in a comprehensive manner.

The use of nuclear power ensures energy security, stabilizes energy and electricity costs, and curbs climate change. The risks posed by nuclear power are likely to be outweighed by the benefits and the resultant advancement of social welfare. Continuous engagement with citizens must be made to promote a deeper understanding of the benefits offered by nuclear power.

When this action is taken, particular attention must be paid to a couple of tendencies. One of these tendencies is that women around the world tend to oppose nuclear power. Table 3 shows that the United States is no exception, with the share of American women who are opposed to nuclear power exceeding that of American men. A deeper understanding of nuclear power should be sought among women by providing them with explanations that have a particular emphasis on economic performance and the risk of accidents.

The other tendency, which is unique to Japan, is that the elderly tend to oppose nuclear power. In contrast, Table 3 shows that elderly people in the United States tend to favor nuclear power more than the younger age groups do. Given this, some creative thinking is required in relation to the way that explanations are offered to the elderly in Japan.

In the United States, direct communication from plant workers is also considered an important way of gaining public understanding of nuclear power. A sense of reassurance can be gleaned when people find plant workers to be trustworthy. It is important for workers from a wide range of age groups to demonstrate how they work, because some people reportedly get worried if they see only young workers who appear inexperienced in their eyes. Ingenuity must be continuously exercised to build public trust.

Table 3 American public opinion broken down by age group and gender

\begin{tabular}{|lll|}
\hline US total & $\begin{array}{l}\text { In favor of nuclear } \\
\text { power }\end{array}$ & $\begin{array}{l}\text { Opposed to nuclear } \\
\text { power }\end{array}$ \\
\hline Male & 57 & 40 \\
\hline Female & 72 & 27 \\
\hline Age 18-49 & 42 & 51 \\
\hline Age 50+ & 53 & 44 \\
\hline Source: Americans still favor nuclear power a year after Fukushima, \\
\multicolumn{2}{l}{ March 2012 } & 34 \\
\hline
\end{tabular}




\section{References}

1) Michael W. Golay: New Energy Technologies: Policy Framework for Macro-Nuclear TechnologyOn Social Acceptance of Nuclear Power, The James A. Baker III Institute for Public Policy of Rice University, August 2001.

2) Foratom: What People Really Think About Nuclear Energy, Europe Atomic Forum, September 2014.

3) BBC World Service Poll: http://www.globescan.com/news-and-analysis/pressreleases/press-releases2011/94-press-releases-2011/127-opposition-to-nuclear-energy-grows-global-poll.html (accessed on April 7, 2016)

4) Wouter Poortinga, Nick Pidgeon, Stuart Capstick, and Midori Aoyagi: Public Attitudes to Nuclear Power and Climate Change in Britain Two Years after the Fukushima Accident, UK Energy Center, January 2014.

5) Gallup: For First Time, Majority in U.S. Oppose Nuclear Energy, Gallup, March 2016 